\title{
Using Information Technology to Study the Construction of Harmonious Relationship between the Police and the People in Public Security Organs under the Public Opinion on Weibo
}

\author{
Jiafei Geng ${ }^{1, a}$, Xiaoli $\mathrm{Wu}^{2, \mathrm{~b} *}$ \\ ${ }^{1}$ Anhui Institute of Public Security Education, Hefei, China \\ ${ }^{2}$ Hefei Binhu VocTional \& Technical College, Hefei, China
}

\begin{abstract}
With the change of people's ideology and concepts, the awakening of the rights of the masses, the division of interests and the continuous change of social conflicts, the relationship between the police and the people is facing many new contradictions and new challenges. Dealing with the public opinion of policerelated microblogs in a reasonable manner quickly and effectively has become an important part of building a harmonious relationship between police and citizens.
\end{abstract}

\section{Instruction}

As an important part of government work in the new socialist period, building a harmonious relationship between the police and the people involves the vital interests of the people and all aspects of government functions, and is related to the effectiveness of the mass work construction carried out by public security organs. From a practical point of view, the author studies the outstanding problems in the current relationship between the police and the public as soon as possible, explores the influencing factors, and puts forward corresponding countermeasures and suggestions to promote the construction of a harmonious socialist society. Which are of great practical significance. Judging from the survey, the relationship between police and citizens in China is generally developing in a healthy manner, but the public's low satisfaction with public security work, the expansion of police responsibilities and the imperfect public security team construction are still outstanding issues that cannot be ignored ${ }^{[1]}$. as follows:

\subsection{The masses are not very satisfied with the public security police}

\subsubsection{Excessive commitment beyond police duties and abilities damages the public security image}

Since the 1990s, Zhangzhou, Fujian 110 in Fujian promised to the society that the public has the slogan of "when there is a police, we must help, we must help, we must rescue, and we must rob" [2]. Think public security organs are omnipotent. However, when the public security organs are unable to satisfy the masses' "difficulties", the masses will think that the public security police do not act and do not really serve the masses to the people, triggering their dissatisfaction with the public security organs and the police, causing tension and disharmony in the relationship between the police and the public.

\subsubsection{Police, direct face of social conflict}

With the rapid development of society, the urbanization process is accelerating, and the number of cases of land acquisition and demolition, land confirmation, and environmental pollution has increased. When public security law enforcement officers deal with these cases, the victims of the case usually socialize through Weibo and other self-media The tool vents resentment and anger on the police and misleads the public and public opinion.

\subsection{The contradiction brought about by the expansion of police powers and responsibilities}

The enlargement of police powers and responsibilities has made some legal definitions unclear or the non-police work of local government's side-scrubbing operations also undertaken by public security organs. This has also become an important hidden danger affecting the harmonious relationship between the police and the public in many parts of my country.

\subsection{Imperfect team building affects public image}

In recent years, under the in-depth development of the government's anti-corruption struggle, a group of corrupt cadres have been selected from the political and legal ranks including the public security system, which has seriously affected the image of the public security ranks among the ranks of the people and lowered the public security police. Goodwill among the masses; some of the

ae-mail: gengjiafei@163.com b*Corresponding Author: Xiaoli Wu,wuxiaoli83@163.com 
policemen are not strong in the concept and purpose of serving the people, and they do not take into account the ideas of the masses in their work, and ignore the communication with the masses.

\section{Data analysis based on Weibo public opinion}

2.1 As China is still in a period of tough reforms, a golden period of development, and a period of prominent contradictions, the gap between the rich and the poor is widening, social distribution is unfair, corruption is endless, people's moral concepts change, and values are also undergoing huge Changes, various social contradictions present unprecedented complexity.

As the main force for resolving contradictions among the people, public security organs can easily become the main targets of Weibo's attention, supervision, hype and even attacks.

According to the public opinion analysis of the relevant online public opinion channel Weibo, we selected the heat change value of the number of original events of a certain Weibo within 10 days from October 22 to 31 , 2019.

Influencing factors: the number of original microblogs $\mathrm{Wy}, \mathrm{i}$; the number of forwarded microblogs Wz,i; the number of comment microblogs $\mathrm{Wp}, \mathrm{i}$; then the formula 1 for calculating the daily public opinion $\mathrm{Oi}$ is:

formula 1: $\mathrm{Oi}=\mathrm{by} \times \mathrm{Wy}, \mathrm{i}+\mathrm{bz} \times \mathrm{Wz}, \mathrm{i}+\mathrm{bp} \times \mathrm{Wp}, \mathrm{i}$

Where i represents the i-th day, by, bz, and bp are the weights of Weibo original number $\mathrm{Wy}$, i, repost number $\mathrm{Wz}, \mathrm{i}$, and comment number $\mathrm{Wp}$, i, respectively, taking $0.45 ; 0.32 ; 0.26$.

The extreme value method is used to simplify the data to obtain the formula2: [3]

formula2: $\mathrm{Oi}^{6}=(\mathrm{Oi}-\mathrm{Min}(\mathrm{Oi})) /(\mathrm{Max}(\mathrm{Oi})-\mathrm{Min}(\mathrm{Oi}))$

Obtain the values of $\mathrm{Oi}$ and Oi' as follows:

\begin{tabular}{|c|c|c|c|c|c|}
\hline Date & Wy,i & Wz,i & $\mathrm{Wp}, \mathrm{i}$ & Oi & $\mathrm{Oi}^{\star}$ \\
\hline October 22 & 345 & 207 & 563 & 367.87 & 0.00393 \\
\hline October 23 & 278 & 179 & 56 & 196.94 & 0.0198 \\
\hline October24 & 98 & 3 & 1 & 45.32 & 0.0026 \\
\hline October 25 & 467 & 150 & 567 & 405.57 & 0.0436 \\
\hline October 26 & 278 & 9 & 6 & 129.54 & 0.0122 \\
\hline October27 & 62 & 2 & 1 & 28.8 & 0.0007 \\
\hline October28 & 50 & 0 & 0 & 22.5 & 0.0002 \\
\hline
\end{tabular}

\begin{tabular}{|l|l|l|l|l|l|}
\hline October29 & 169 & 0 & 5 & 76.05 & 0.0061 \\
\hline October30 & 1562 & 5432 & 7638 & 4427.02 & 0.5012 \\
\hline October31 & 18579 & 680 & 895 & 8810.85 & 1 \\
\hline
\end{tabular}

2.2 Data analysis. According to the Oi' data in the above table, we can make a distribution diagram of public opinion heat values as follows:

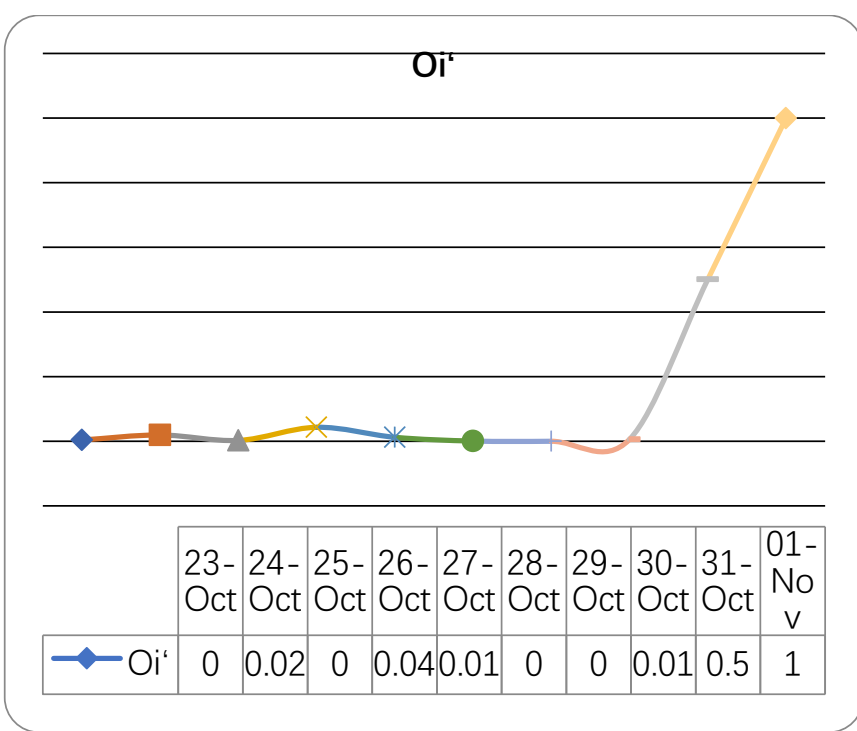

Fig 1. Distribution map of public opinion heat value The popularity value refers to the degree of attention of the person or event among netizens in the information of the entire network.

From this we can find that in the beginning stage: October 22-October 24, the attention is not high, the attention on the 25 th and 26th rose slightly, and then fell, and on October 29-31, the attention quickly soared. Through the process of the development and change of the heat value, we found that the initial stage of the incident was not highly concerned, the people's emotions were stable, and the dissatisfaction was low. With the development of the incident, the public's attention has increased slightly, indicating that the incident has aroused public attention and the incident must be dealt with. If no measures are taken at this time, then on the 29th, public opinion will rise rapidly, the opportunity will be lost, and it will be in a passive position.

Through analysis, we know that rapid processing is the best measure to reduce public opinion and the key measure to improve the harmonious relationship between the police and the public.

\section{Exploration of the construction model of harmonious relationship between the police and the people}

3.1 Improve the channels for social confession, improve the mechanism for expressing appeals, and eliminate dissatisfaction at an early stage. 
Improving the channels of public confessions and improving the expression mechanism of appeals are of great benefit in venting the emotions of the people and alleviating social conflicts.

\subsubsection{Establish and improve the multi-channel government petition system}

In addition to setting up full-time letters and visits agencies, local party committees and governments should also actively exercise the letters and visits functions of discipline inspection and supervision, public security, judicial and other discipline enforcement and law enforcement supervision agencies, and share the pressure of letter and visit departments.

\subsubsection{Establish and improve the way of expressing the interests of the public}

Weaken the role and role of local governments in the expression of social interest claims, and prevent local governments from becoming "referees" and "athletes"; appropriately increasing the channels for expressing daily appeals from the bottom of society and vulnerable groups, Regulate and restrict the abnormal or gray expression channels of socially powerful groups, so as to benefit the social people who really need it [4].

\subsection{Create a civilized, harmonious and friendly socialist core value}

Values are the soul and foundation of society. In a soberminded and honest society, the public must have good social values. The correct values are of great significance for alleviating social contradictions, reducing public security pressure, and maintaining social security and stability.

\subsubsection{To strengthen publicity}

Give full play to the role of online media, carry out allround publicity through various channels such as WeChat, Weibo, and mobile APP, help the public to establish a correct outlook on life and values, and let socialist core values penetrate into the hearts of the people.

\subsubsection{Lead by example, deliver positive energy}

Local party committees and governments can carry out advanced person selection activities according to local conditions, tap outstanding social figures, set up positive examples of the society, and through the in-depth mining and reporting of model stories, show the correct value pursuit orientation for the public [5]. To establish a harmonious relationship between the police and the public, the public security organs must give full play to their leading role in the relationship between the police and the public, and take the promotion of the "two senses" of the masses as their working goal. Work hard to do our own work, earnestly deepen the close contact with the masses, strengthen the party style and clean government construction of the public security team, resolutely combat the corruption and corruption of the public security team, and correct the bad wind. Further improve the purity of the public security team, increase supervision, strictly enforce the law in a civilized manner, create a publicity position, and shape the image of a high-quality public security team serving the people.

\subsection{Deepen the close contact with the masses and pay attention to the direction of public opinion}

\subsubsection{Improve the mechanism, strengthen the awareness of public relations, and improve the communication channels with the masses}

The foundation of the harmonious relationship between the police and the people is communication and exchanges, and the basis for public security organs to do their job is to truly understand the needs of the people, from the people, to the people, to transform the reasonable needs of the people into the motivation to improve public security work. Give full play to the advantages of network communication and interaction, and strengthen active communication with netizens; grassroots public security departments should clarify their responsibilities, take root in the work of the masses, arrange police force reasonably, allow more grassroots police to go deep into the community and streets to carry out mass work, and explore grassroots police in the new era Business mode[6].

\subsubsection{Implement open police affairs, strengthen supervision by the masses, and make police work zero distance from the masses}

Give full play to the power of the masses and establish a normal mass supervision mechanism.

Enhance the transparency and credibility of public security work, and let power operate in the sun.

The openness and fairness of public security work will inevitably shorten the actual distance from the masses, facilitate communication with the masses, and further gain the understanding and support of law-abiding citizens, which will also be very beneficial to the daily work of public security.

\subsubsection{Actively do a good job in the public security petition work}

Actively carry out investigation and resolution of conflicts and disputes concerning public security laws and lawsuits. Deepen the leadership visit day activities, from the original one day a week to two or three days a week; Implement the responsibility system for letters and visits, integrate the effectiveness of letters and visits into the annual work evaluation, strengthen the importance of letters and visits, achieve special cases, and improve the quality of letter and visit cases and the rate of interest suspension. It is necessary to improve institutionalized communication mechanisms such as public hearings, 
listen to the opinions of the masses, take the solution of the practical difficulties of the masses as a starting point, balance various interests, resolve conflicts, and resolve disputes.

\subsection{Create an influential public security position}

Public security organs must further strengthen the construction of police public relations, increase the influence of public security propaganda, and actively communicate and communicate with the people to let the public understand the policies and policies of public security work, as well as the fact that the police have worked hard and silently to correctly understand and evaluate Police behavior.

\subsubsection{Build a high-quality public security publicity team}

The public security publicity department should recruit a group of high-quality publicity personnel with public relations enthusiasm, professional knowledge of publicity, and certain organizational management and adaptability[8]. Increase the training of public opinion comrades in the public opinion, media communication, and create a good image of the police to improve the quality and ability of the public security propaganda team.

\subsubsection{Change the traditional propaganda model and build a new idea of public security propaganda of "police-civilian interaction, public security guidance"}

Further strengthen the "two micro-ends" (Weibo, WeChat, news client) own publicity platform, actively carry out interactive communication with netizens, understand the latest developments in online public opinion, and guide the false negative police-related negative information in a budding state And clarify to prevent its further deterioration.

When constructing a harmonious relationship between the police and the public, the public security organs must strive to strengthen communication with the masses, strengthen their own construction, and shape the law enforcement of public security polices. Good values, cultivate the legal literacy of citizens, and form a mutually beneficial and win-win police-civilian cooperation concept, thereby truly forming a situation of multi-party participation and jointly building a harmonious policecivilian relationship.

\subsection{Strengthen the self-construction of the public security team}

\subsubsection{Strengthen the core idea of law enforcement for the people}

The most important thing in the relationship between the police and the people is the service relationship between the police and the people. This is the essential manifestation of the people's public security for the people, and it is the foundation of the harmonious police-civil relationship in the new era of socialism. Power is tied to the people, benefits are sought by the people, serve the people wholeheartedly, win the love and support of the people, and lay a solid foundation for a harmonious relationship between the police and the people .

\subsubsection{Construct a multi-faceted and three- dimensional public security supervision system}

At present, there are still certain shortcomings and defects in the supervision system and mechanism of public security organs in our country. In the actual supervision work, due to human conditions or other reasons, the supervision effect is not obvious. Therefore, it is necessary to build a three-in-one supervision mechanism for discipline inspection, inspection, and the masses, so that the masses can participate in the supervision of public security police, and build a clean and honest people's police force.

\subsubsection{Strengthen the overall management of non- staff personnel such as co-police}

The police and other non-staff personnel are in the public security system in large numbers. At the same time, the police and other non-staff personnel also represent the image of the police. If something goes wrong, the people will also think it is a police problem. Therefore, the public security organs need to improve the criteria for the recruitment and assessment of non-staff personnel such as co-police officers, to have a comprehensive understanding of the overall quality of the assessors, and to prevent personnel with criminal records or social inferiority from entering the public security team; Strengthen the business training of the legal knowledge and job skills of the nonstaff personnel such as the police association, and promote the improvement of the overall comprehensive quality of the non-staff personnel.

\subsection{Deepen the policing strategy of grassroots communities}

The foundation of social security and stability lies in grassroots communities. Only when grassroots communities achieve peace and harmony can society achieve long-term stability and harmonious police-civilian relations can be maintained for a long time.

The decision-making leadership of the public security department should adopt strong measures to require all localities to sink the police force and deploy full-time community police in the community. The target of the police is the community, the scope is the grassroots jurisdiction, and they are responsible for the basic policing of the community. Work to improve the rate of seeing the police and the level of public service.

\subsubsection{Create a harmonious and warm community atmosphere}

Cultivate the concept of "community is my home, safety 
depends on everyone" for the participation of police and citizens, fully mobilize the role of community neighborhood committees and street offices, and jointly carry out a variety of activities such as police talks and tea parties, door-to-door interviews, etc. Analyze the causes of frequent cases and anti-theft measures for community residents by means of public security notifications and police case analysis, so as to increase the benefits of community residents' joint governance and the construction of a safe community with the police.

\subsubsection{Improve the grassroots policing system and improve the new type of community security management system}

The community police should use the community police office as a platform to closely integrate the creation of a harmonious and safe community with community policing and drug-free communities. Use the formed good community atmosphere and mass resources to strengthen public security intelligence information work, promptly discover and eliminate possible unstable factors in the jurisdiction, and continuously strengthen and improve the current public security management and prevention work of grassroots communities in the current state of social population flow.

\section{Conclusion}

Building a harmonious relationship between the police and the people is a multi-dimensional and comprehensive system engineering. Under the leadership of the party and the country, public security organizations in our country have always regarded mass work as a top priority and top priority. Only when they are in close contact with the masses can the public security police have a solid mass foundation, can public security work develop substantially, hence the harmony and stability of the social and the longterm peace of the country can be sustained.

\section{References}

1. An Qingrong. Thoughts on building a harmonious relationship between the police and the people [J]. Journal of Yunnan Police Officer Academy, 2010(01): $82-85$

2. Zhao Biao, Wang Yongbing. Thoughts on the construction of a benign interaction mechanism between the police and the people in a harmonious society [J]. Journal of Guizhou Police Officer Vocational College, 2006, 18(06): 86-89

3. Zhang Yarong. Evolution analysis of police-related public opinion based on subject discovery[D]. Beijing: People's Public Security University of China, 2016: 42-43

4. Li Mingshan. Analysis of the performance and causes of the current mismatch between the police and the people [J]. Journal of Gansu Police Vocational College, 2010,08(01): 6-8

5. Yin Weizhong, Zhang Mansheng. Community policing from the perspective of harmonious society theory $[\mathrm{M}]$. Beijing: People's Public Security University Press, 2007: 276-277

6. Zhu Shuyang, Jiang Xiuqin, Tan Zhimin. Research on the cultivation path of socialist core values based on knowledge, faith, promise and behavior [J]. Journal of Hubei Correspondence University, 2015, 28(17): 5960

7. Hou Mengchen. A Brief Discussion on the Neutralization Strategy of Contradictions between Public Security Service and Violent Organs [J]. Legal Expo, 2017(03): 237

8. Zeng Decai. Thoughts on the implementation of community policing strategy based on community resources [J]. Shanxi Police College, 2005, 13(01): $41-42$ 